\title{
Sleep apnoea and the heart
}

\author{
Patrick Lévy ${ }^{1,2}$, Silke Ryan ${ }^{3,4}$, Olaf Oldenburg ${ }^{5}$ and Gianfranco Parati6,7 \\ Affiliations: 'Univ. Grenoble Alpes, Hypoxia Physiopathology (HP2) Laboratory, Grenoble, and ${ }^{2}$ NSSERM, HP2 \\ laboratory, U1042, Grenoble, France. ${ }^{3}$ Sleep Research Laboratory, St. Vincent's University Hospital, Dublin, and \\ ${ }^{4}$ School of Medicine and Medical Sciences, The Conway Institute, University College Dublin, Ireland. ${ }^{5}$ Dept of \\ Cardiology, Heart and Diabetes Centre North Rhine-Westphalia, Ruhr University Bochum, Bad Oeynhausen, \\ Germany. ${ }^{6}$ Dept of Clinical Medicine and Prevention, University of Milano-Bicocca, Milan, and ${ }^{7}$ Dept of \\ Cardiology, S. Luca Hospital, Istituto Auxologico Italiano IRCCS, Milan, Italy.
}

Correspondence: P. Lévy, INSERM U1042, Université Joseph Fourier, BP 53, 38041 Grenoble, Cedex 9, France. E-mail: Patrick.levylaujf-grenoble.fr

ABSTRACT Sleep apnoea is associated with significant daytime functioning impairment and marked cardiovascular morbidities, leading to a significant increase in mortality. Sympathetic activation, oxidative stress and systemic inflammation have been shown to be the main intermediary mechanisms associated with sleep apnoea and intermittent hypoxia. There are now convincing data regarding the association between hypertension, arrhythmias, coronary heart disease, heart failure, increased cardiovascular mortality and sleep apnoea. This has been evidenced in sleep apnoea patients and is supported by experimental data obtained in intermittent hypoxia. Whether treating sleep apnoea enables chronic cardiovascular consequences to be reversed is not fully established as regard coronary heart disease, arrhythmias and heart failure. In this late condition, complex bidirectional relationships occur, with obstructive sleep apnoea being a risk factor for heart failure whilst central sleep apnoea mainly appears as a consequence of heart failure. It remains to be established in adequately designed studies, i.e. large randomised controlled trials, whether treating sleep apnoea can improve heart failure morbidity and mortality.

@ERSpublications

Sleep apnoea is associated with arrhythmias, coronary disease and heart failure through intermittent hypoxia http://ow.ly/ne19T

\section{Introduction}

Obstructive sleep apnoea (OSA) is a well-known public health problem owing to its high prevalence and the numerous consequences of the disorder, including excessive daytime somnolence [1] and cognitive impairment [2], as well as cardiovascular [3] and metabolic [4] morbidity. Thus, there is an excess in cardiovascular mortality that has been repeatedly reported in longitudinal cohorts in both general [5] and clinical [6] populations. Despite many confounding factors, including age, sex and obesity, there is accumulating evidence regarding strong associations between OSA, cardiovascular diseases [7], i.e. hypertension [8,9], coronary artery disease (CAD) [10], cerebrovascular disease [11] and heart rate, conduction disorders [12-14] and excess mortality $[5,6,15]$. However, it seems that this is mainly true before the age of 70 years $[5,16]$. In older patients, the cardiovascular risk does not seem to be increased compared to non-OSA, at least for hypertension and CAD.

OSA causes myocardial as well as arterial damage $[3,7]$. Untreated OSA might, therefore, promote the progression of cardiac disease, resulting in heart failure and increased mortality in patients with heart failure $[17,18]$. In this paper, reporting a symposium from the Sleep and Breathing meeting held in Berlin in May 2013, we have reviewed the mechanisms by which sleep apnoea is promoting heart and vessel damages. We will also describe three major cardiac morbidities associated with sleep apnoea: $\mathrm{CAD}$, arrhythmia and heart failure.

Received: June 162013 | Accepted after revision: July 162013

Conflict of interest: Disclosures can be found alongside the online version of this article at err.ersjournals.com

Provenance: Submitted article, peer reviewed.

Copyright @ERS 2013 


\section{Basic mechanisms linking OSA and cardiovascular diseases}

OSA is associated with the development of various cardiovascular diseases and this association now represents a significant public health burden [3]. The identification of the mechanisms underlying the cardiovascular disease processes is of major importance and, despite significant effort being made, the process remains incompletely understood. Clinical studies using OSA populations have often been limited by inadequate control for frequent comorbid conditions, in particular obesity, pre-existing cardiovascular disease or medications. Moreover, OSA is a complex and heterogeneous disease and differences in morphology and length of the nocturnal airflow cessations and associated oxygen desaturations, which are not captured by the traditional OSA severity marker, as well as differences in duration of the disease prior to diagnosis are major contributors for the large variability observed between studies results, including differences in response to short-term continuous positive airway pressure (CPAP) therapy. Cell culture and animal models have been developed to overcome some of these hurdles. These models allow single components of the disease to be studied; precisely controlling the triggering events in both severity and duration, and providing genetic homogeneous populations. Thus, in vitro and animal studies have greatly contributed to our current knowledge.

OSA comprises various pathophysiological triggers, but beside sleep fragmentation, intrathoracic pressure swings and recurrent hypercapnia, it is the OSA unique form of hypoxia in particular, with repetitive short cycles of desaturation followed by rapid re-oxygenation, termed intermittent hypoxia, that plays a pivotal role in the cardiovascular disease process. The pathogenesis is probably multifactorial and our current concept involves sympathetic nervous system overactivity, systemic inflammation and oxidative stress leading to endothelial dysfunction and, possibly, metabolic dysfunction which are the most important pathways (fig. 1) [3, 19].

However, it should be noted that some beneficial effects of intermittent hypoxia have been evidenced in both animal models and OSA with regard to long-term facilitation and hypoxic ventilatory response [20, 21]. Exposure to acute intermittent hypoxia or repeated carotid sinus nerve stimulation causes a persistent increase in respiratory activity [20]; whether this is beneficial in OSA remains unknown. It has been suggested that alteration in long-term facilitation and hypoxic ventilatory response in reply to intermittent hypoxia exposure could lead to breathing stability and reduction in apnoea/hypopnoea index, although this is still conflicting [22]. There are also potential beneficial effects with regard to cardiovascular consequences that have been suggested in animals exposed to intermittent hypoxia [23-25]. This might also be the case in OSA with respect to vascular adaptations $[26,27]$ and possibly lower mortality [16].

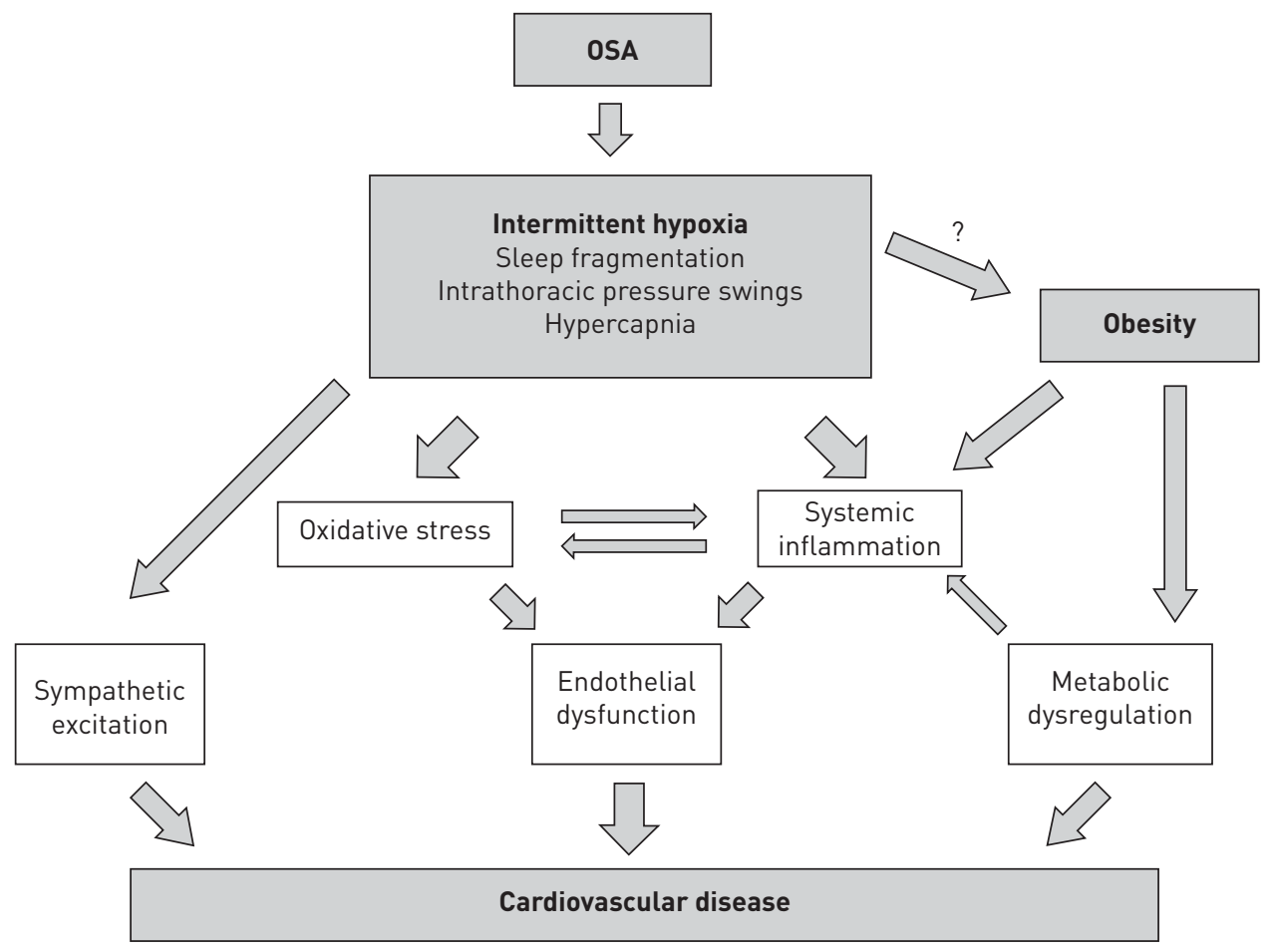

FIGURE 1 Main mechanisms linking obstructive sleep apnoea (OSA), intermittent hypoxia and cardiovascular diseases. 
Sympathetic nervous system overactivity

Sympathetic excitation in the pathogenesis of systemic arterial hypertension in OSA has been suggested for many years and this is based on early observations of increased urinary catecholamine levels in OSA patients with a significant fall following tracheostomy [28]. Other studies have confirmed elevated catecholamine levels both in plasma and urine of OSA patients $[29,30]$ and also a significant fall with CPAP therapy [31, 32]. Using microneurography as a more direct measurement of sympathetic nervous system activity, SOMERS et al. [33] demonstrated increased muscle sympathetic nervous activity (MSNA) during wakefulness in OSA versus obese controls. MSNA also correlated with noradrenaline levels [34] and treatment with CPAP therapy significantly lowered MSNA [35].

Support for the role of sympathetic overactivity in the pathogenesis of hypertension in OSA also comes from animal models. In a dog model of OSA, an increase in blood pressure was found which declined once the repetitive airway occlusion during sleep was abolished [36]. FLETCHER et al. [37] developed a rodent model of intermittent hypoxia which still provides the basis for most intermittent hypoxia animal models to date. In a series of elegant experiments, the author's demonstrated persistent elevation of blood pressure in response to intermittent hypoxia but, by pharmacological and surgical blockage of the sympathetic nervous system, this blood pressure increase was abolished [38-40]. Recently, TAMISIER et al. [41] developed a human model of intermittent hypoxia and, similar to the animal studies, short-term exposure to intermittent hypoxia resulted in daytime blood pressure elevation with an associated increased in MSNA.

Several neural and humoral mechanisms probably contribute to the maintenance of higher sympathetic activity. This includes a potentiation of the peripheral chemoreflex to hypoxia in OSA [42]. Furthermore, various studies during sleep and wakefulness have shown depressed baroreflex sensitivity as an established index of cardiac sympatho-vagal imbalance in OSA patients and improvement with CPAP therapy [43-45].

\section{Systemic inflammation}

Over the past few years, there has been accumulating evidence of a causal relationship between OSA and the development of atherosclerosis and associated diseases. This has been supported by numerous studies demonstrating impaired endothelial function and signs of early atherosclerosis, such as increased carotid intima-media thickness in OSA and improvement with effective CPAP therapy [46-52]. In support of a key role of intermittent hypoxia in this process, the severity of the nocturnal oxygen desaturation has been shown to be predictive of subclinical atherosclerosis [46]. In C57BL/6J mice fed on a high cholesterol diet, treatment with intermittent hypoxia induced atherosclerosis which was not observed in animals treated with control conditions [53]. Similarly, in atherosclerosis-prone apolipoprotein-E deficient mice (ApoE ${ }^{-/-}$), intermittent hypoxia led to a significant acceleration of the atherosclerotic process when using high-fat [54] or normal diet-fed animals [55]. Even in non-genetically modified animals fed with a normal diet, intermittent hypoxia led to early changes including downregulated endothelial Platelet endothelial cell adhesion molecule-1 (a marker of vascular remodelling) expression at the aortic and cardiac levels suggesting endothelial dysfunction or an early event of atherogenesis [56]. ARNAUD et al. [57] further evidenced that inflammatory pre-atherosclerotic remodelling was involved since systemic inflammation, as well as structural and inflammatory vascular alterations, occurred after 2 weeks of intermittent hypoxia. Leukocyte-endothelium adhesive interactions were increased, attested by leukocyte rolling and intercellular adhesion molecule (ICAM)-1 expression in mesenteric vessels. Aortas had increased intima media thickness [57]. Systemic inflammation plays a pivotal role in all stages of atherosclerosis in general [58] and hence, not surprisingly, it is also central in intermittent hypoxia-induced pathogenesis. ARNAUD et al. [55] demonstrated that inflammation at systemic and vascular levels contributes to the intermittent hypoxia atherogenicity in the $\mathrm{ApoE}^{-/-}$mice. Various studies have addressed interactions between the vascular endothelium and inflammatory cells in OSA. There is an increase in adhesion molecules promoting these interactions [59]. Moreover, DyUgovsKaya et al. [60] demonstrated that lymphocytes of OSA patients acquire an activated phenotype with increased cytotoxicity against endothelial cells associated with increased intracellular content of the pro-inflammatory mediators tumour necrosis factor (TNF) $\alpha$ and interleukin (IL)-8, and a decrease of the anti-inflammatory cytokine IL-10.

Activation of the transcription factor nuclear factor (NF)- $\mathrm{\kappa B}$ appears central in the intermittent hypoxiainduced inflammation. NF- $\kappa \mathrm{B}$ is the master regulator of an inflammatory response and numerous inflammatory genes, such as TNF- $\alpha$, IL- 8 or ICAM-1, which are also known to be pro-atherogenic, are under its control. NF- $\kappa \mathrm{B}$ activation has been demonstrated in cardiovascular tissue from mice treated with intermittent hypoxia and in cultured monocytes from OSA patients [61, 62]. Using a cell culture model of intermittent hypoxia, RYAN et al. [63] demonstrated a preferential activation of NF- $\mathrm{BB}$-dependent proinflammatory pathways by intermittent hypoxia over adaptive hypoxia-inducible factor (HIF)-1 mediated pathways, which is in contrast to sustained hypoxia where adaptive pathways predominate. 
Levels of circulating downstream products of NF- $\mathrm{BB}$ activation have been found to be increased in OSA patients versus controls, and CPAP therapy has a beneficial effect on these levels [19, 64, 65].

\section{Oxidative stress}

Although supporting data are sparse and results are inconsistent, OSA-related repetitive episodes of hypoxia and re-oxygenation have generally been associated with increased production of reactive oxygen species and, thus, are thought to promote oxidative stress. Several studies identified increased concentration of lipid peroxidation biomarkers in OSA patients and a significant decline with CPAP therapy [66, 67]. Rats exposed to chronic intermittent hypoxia showed increased lipid peroxidation which correlated with left ventricular dysfunction [68]. There is evidence for the involvement of oxidative stress in the development of endothelial dysfunction in OSA. Intravenous administration of the antioxidant vitamin $\mathrm{C}$ resulted in acute improvement of endothelium-dependent vasodilation [69]. Furthermore, JeLIC et al. [70] detected higher NF- $\kappa \mathrm{B}$ activity in freshly harvested venous endothelial cells as well as higher levels of the oxidative stress marker nitrotyrosine in OSA patients and reported a significant fall with CPAP therapy suggesting interaction of oxidative stress and inflammation.

Nevertheless, large studies failed to show a beneficial effect of antioxidant therapy on coronary and cerebrovascular disease and oxidative stress could potentially be a consequence rather than a cause of vascular inflammation and subsequent atherosclerosis [71].

\section{Metabolic dysfunction}

There is fast accumulating evidence of an association of OSA with glucose and lipid dysfunction; however, it is still unclear if this occurs independent of obesity. There are probably complex interactions between intermittent hypoxia, adipose tissue and metabolic functions which are still poorly explored. State-of-theart reviews on this subject have been published recently [4].

\section{Glucose metabolism}

OSA is associated with increased prevalence of type 2 diabetes [72] and higher HbA1C-levels in nondiabetic subjects [73]. Numerous studies have investigated the impact of OSA on insulin resistance. The Sleep Heart Health Study, performed in 2656 individuals, showed that OSA severity was associated with insulin resistance after adjustment for obesity [74] and, in a large Swedish population study on females, OSA was independently associated with insulin sensitivity [75]. Similar data have been obtained in samples of OSA patients, with the majority revealing positive associations [4]. Chronic intermittent hypoxia greatly exacerbates insulin resistance and glucose intolerance in obese leptin deficient ob/ob mice and in dietinduced obese C57BL/6J mice; however, the effect was not seen in lean littermates suggesting an additive role of both intermittent hypoxia and obesity in this process $[76,77]$.

The effect of CPAP therapy on glucose metabolism is still controversial and various randomised controlled trials failed to show a benefit [78-80], although others were clearly positive [81]. Selection differences, comorbidities, adherence to treatment i.e. CPAP compliance, and short treatment duration may explain these differences. For instance, an observational study in a highly selected sample of OSA patients found improved insulin sensitivity in patients with good compliance to CPAP after 2.9 years of treatment [82]. Ongoing studies may help to clarify this issue [83].

Lipid metabolism

Dyslipidemia is prevalent among OSA patients. However, an independent association between OSA and increased levels of total cholesterol, low-density lipoprotein and triglycerides is not yet clearly proven. Most studies were not specifically designed to evaluate lipid profile and have been influenced by potential confounders $[84,85]$. CPAP therapy may also have a positive effect on lipid profile but there is a lack of long-term data [86]. Mice studies have shown that intermittent hypoxia is a direct cause of hyperlipidaemia with severity being proportional to the severity of the intermittent hypoxia stimulus [87].

\section{Future directions}

There is a clear need for large-scale collaborative studies of carefully defined patient populations that are adequately controlled for potential confounders. Future studies should also seek to identify the interactions between different pathophysiological pathways and, in particular, the interaction of OSA and obesity. Understanding the basic molecular mechanisms of cardiovascular complications in OSA can help to fill the gap of missing epidemiological evidence and, therefore, additional translational studies involving cell, animal and human models are strongly required.

Key findings and practical points

Although OSA involves different physiological triggers, i.e. sleep fragmentation, intrathoracic pressure swings and recurrent hypercapnia, the short cycles of intermittent hypoxia associated with repeated 
complete or partial cessations of breathing plays a pivotal role in the cardiovascular disease process. Intermittent hypoxia is associated with sympathetic nervous system overactivity, systemic inflammation and oxidative stress leading to endothelial dysfunction and, possibly, metabolic dysfunction as the most important pathways. The best experimental and clinical evidence linking OSA, intermittent hypoxia and cardiovascular diseases involve systemic hypertension, early atherosclerosis and endothelial dysfunction. As regards metabolic dysfunction, there are complex interactions between intermittent hypoxia, adipose tissue and metabolism. This might explain why OSA and intermittent hypoxia effects on glucose and lipid metabolism are difficult to separate from obesity per se.

\section{Sleep-disordered breathing and cardiac arrhythmias}

Cardiac arrhythmias are common in patients with sleep-disordered breathing (SDB). The prognostic relevance of these rhythm disturbances is highly dependent on the presence of underlying heart disease in addition to arrhythmia.

\section{Premature atrial or ventricular complexes}

Premature atrial complexes (PAC), or even ventricular complexes (PVC), can be detected in healthy hearts and are triggered by a variety of stimuli such as caffeine, alcohol, acute infection, electrolyte imbalance and many others, including SDB. In patients with no underlying heart disease, PAC or PVC are of little or no prognostic relevance. In patients with cardiac disease, PAC or PVC do have some predictive value, but are nonspecific and therefore are not particularly helpful. Thus, in sleep studies, documentation of PAC and/or PVC cannot be interpreted without the context of a patient's medical history. However, sleep is usually accompanied by a reduction in PVC [88] meaning that a high number of PVCs at night could be a marker of sleep disorders.

\section{Ventricular arrhythmias in heart failure}

SDB is highly prevalent in patients with structural heart disease, such as heart failure secondary to reduced ejection fraction [89], and is independently associated with the occurrence of malignant ventricular arrhythmias [90]. In a cohort of heart failure patients treated according to current guidelines, including cardiac resynchronisation therapy with defibrillators, obstructive and especially central sleep apnoea (CSA) were found to be independent predictors for the first detection of malignant arrhythmias and their appropriate therapy by anti-tachycardic pacing or defibrillator shocks (fig. 2) [90]. Subsequently, observational data showed that treatment of CSA using adaptive servo-ventilation (ASV) therapy was associated with a decrease of malignant arrhythmic events [91].

\section{Atrial fibrillation}

Like SDB, the incidence and prevalence of atrial fibrillation increases with age [92]. Analyses of circadian variation in atrial fibrillation incidence show a clear night-time peak [93] and OSA was shown to be

FIGURE 2 Kaplan-Meier plot on appropriate cardioverter-defibrillator therapies arranged according to mild or no sleepdisordered breathing (SDB), obstructive sleep apnoea (OSA) and central sleep apnoea (CSA) (cut-off apnoea/hypopnoea index $\geqslant 15$ events $\left.\cdot h^{-1}\right)$. Reproduced from [90].

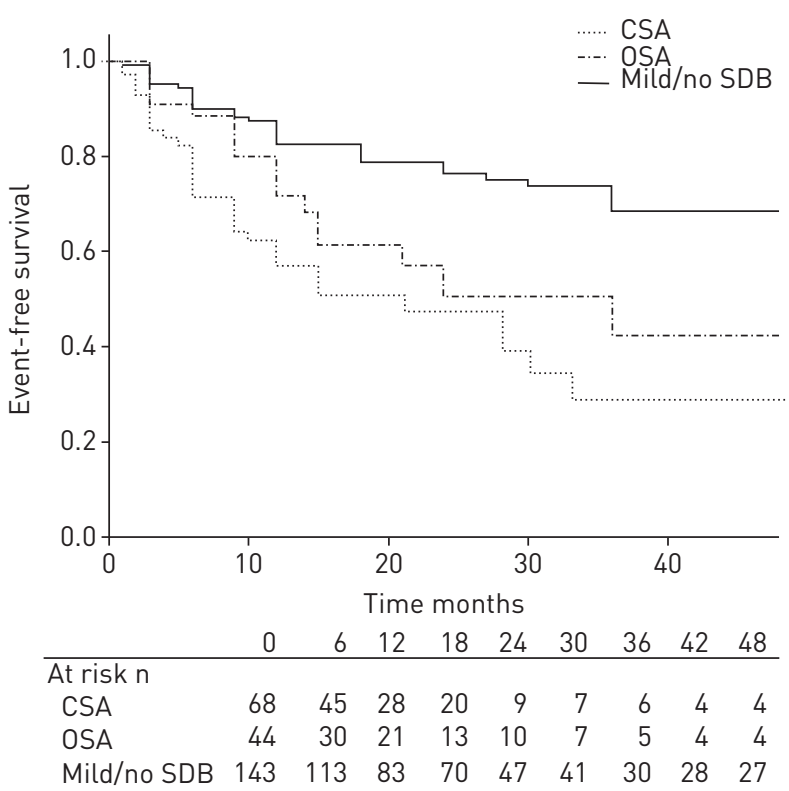


independently associated with an increased risk of atrial fibrillation [12, 13]. In turn, atrial fibrillation was associated with an increased risk of stroke, systemic embolism [94] and death [95, 96].

The prevalence of SDB in patients with atrial fibrillation admitted for electrical cardioversion is 75\% [97]. In the Sleep Heart Health Study, OSA was independently associated with the occurrence of atrial fibrillation [12]. In addition, patients with OSA are characterised by an enlarged left atria [98], longer P-wave duration on the ECG [99] and (negative) electrical and structural atrial remodelling [100, 101]. However, ablation therapy for atrial fibrillation might have the potential to decrease OSA severity [102].

Before the invention of CPAP, use of tracheostomy to treat severe OSA was shown to decrease nocturnal cardiac arrhythmias and conduction abnormalities, including the occurrence of atrial fibrillation [103]. Subsequently, CPAP was able to significantly reduce nocturnal bradycardias and pauses in patients with OSA [104].

The odds of achieving stable sinus rhythm after electrical cardioversion can be doubled if OSA is treated with CPAP compared with being left untreated [105]. In addition, anti-arrhythmic drug therapy for atrial fibrillation seems to be less effective in untreated patients with severe OSA [106].

Ablative therapies for atrial fibrillation, radiofrequency or cryo-balloon ablation are less efficient in patients with moderate-to-severe SDB than in those without SDB or with only mild SDB [107, 108]. Conversely, the effectiveness of pulmonary vein isolation therapy in patients with atrial fibrillation and OSA appears to improve when OSA is effectively treated using CPAP [109]. In this context it needs to be emphasised that appropriate diagnostic tools need to be used to detect SDB in patients with atrial fibrillation [110], like those that should be implemented for most cardiac patients [111]. Questionnaires, even the Berlin Questionnaire, do not appear to be appropriate for the detection of OSA patients with heart disease and/or atrial fibrillation, and more specific screening devices are recommended.

In summary, OSA is recognised as an independent and modifiable risk factor for AF. Effective treatment of OSA is recommended by the electrophysiological societies of both Europe and North America [112].

\section{The problem of surrogate markers}

Evidence-based medicine plays an important role in patient care across many disciplines, including cardiology. Outcome studies make an important contribution to evidence-based medicine, and these are needed in the field of SDB. The danger of using surrogate end-points was highlighted by the results of the Cardiac Arrhythmia Suppression Trial (CAST) [113] which showed that class I anti-arrhythmic agents effectively suppressed PVC but that this was not associated with mortality benefit, with cardiac arrest and death being actually increased in treated patients. With this in mind, outcome studies will be important for determining the impact of treating SDB in all patients, including those with heart disease and/or cardiac arrhythmias.

\section{Key findings and practical points}

Cardiac arrhythmias are common in patients with SDB. Their significance is highly dependent on the presence of underlying heart disease and on the type of arrhythmia. A high proportion of PVC may be a marker of sleep disorders. Sleep apnoea is predictive of malignant arrhythmias in heart failure patients. This is more predictive for CSA than OSA. OSA is recognised as an independent and modifiable risk factor for atrial fibrillation. Effective treatment of OSA is recommended by international guidelines. Diagnosis and treatment of OSA in case of arrhythmias are recommended. Whether simplified techniques may be used for screening and diagnosis remains to be seen. Treatment of OSA does not differ from usual OSA management besides careful cardiovascular evaluation at baseline and during follow-up involving a cardiologist. Implanted devices in cardiac patients, i.e. pace makers, defibrillator, etc., could possibly help in OSA screening when already pre-existing in cardiac patients, by extracting a respiratory signal.

\section{SDB and coronary heart disease}

Patients with OSA may also present with major cardiovascular risk factors, such as hypertension, diabetes mellitus, dyslipidaemia and obesity or overweight that all can affect cardiac structure and function [7, 9]. Thus, OSA and these risk factors may explain the increased prevalence of CAD in patients with OSA $[7,114]$.

\section{Clinical data}

Clinical data from cross-sectional and prospective studies suggests an association between OSA and CAD [10, $115,116]$. OSA is associated with an increased risk of cardiovascular mortality in patients with CAD [115]. There is also possible inhibition of left ventricular function recovery after acute myocardial infarction [117]. 
General population cohorts

CAD causes coronary heart disease (CHD), which can lead to heart failure. In studies in the general population i.e. the Sleep Heart Health Study, the cross-sectional analyses showed a weak relationship between OSA severity and the relative risk of CHD [118]. In 6424 individuals, a total of 1023 (16\%) participants reported at least one manifestation of cardiovascular disorder (myocardial infarction, angina, coronary revascularisation procedure, heart failure or stroke). SDB was associated more strongly with selfreported heart failure and stroke than with self-reported CHD: the relative odds ratio (95\% confidence interval) of heart failure, stroke and coronary heart disease (upper versus lower AHI quartile) were 2.38 (1.22-4.62), 1.58 (1.02-2.46), and 1.27 (0.99-1.62), respectively [118]. In the prospective part of the study, in which 4422 participants free from CHD and heart failure at baseline were enrolled, OSA was found as an independent predictor of incident CHD [19]. After adjustment for multiple risk factors, OSA was a significant predictor of incident CHD (myocardial infarction, revascularisation procedure or CHD death) only in males aged $<70$ years (adjusted hazard ratio 1.10 (95\% CI 1.00-1.21) per 10-unit increase in AHI) but not in older males or in females of any age. Among males aged $40-70$ years, those with AHI $\geqslant 30$ were $68 \%$ more likely to develop CHD than those with an AHI $<5$. With regards to females, it should be noted that there is a lack of power, particularly since the most severe OSA quartile is poorly represented. The mechanisms by which the relationship between OSA and CHD is lost after 70 years of age remain unclear. There may be a selection of non-responders to sleep apnoea and/or intermittent hypoxia. There are also potential protective mechanisms, at least in cases of mild OSA [27].

\section{CHD imaging evidence}

In more recent clinical data, there is also direct evidence regarding the relationship between OSA and CHD. Recently, KENT et al. [119] performed coronary computed tomography angiography and inpatient attended sleep studies on a cohort of otherwise healthy males attending the sleep laboratory. In this prospective casecontrol study, they compared coronary artery plaque volume between subjects with low and high AHI, who were otherwise comparable for demographic, anthropometric and clinical variables. Coronary plaque volume was significantly greater in the high AHI group and, furthermore, correlated significantly with AHI (fig. 3) [119].

\section{Treatment effects}

There have been several uncontrolled studies suggesting a beneficial effect on CHD morbidity and survival. A prospective non-randomised study with a median follow-up of $86.5 \pm 39$ months reported that treatment of OSA using either CPAP or upper airway surgery in CAD patients was associated with a decrease in the occurrence of new cardiovascular events and an increased time-to-event [120]. Other uncontrolled studies evidenced a benefit. In a retrospective study, treated OSA had a statistically significant decreased number of cardiac deaths on follow-up when compared with untreated OSA patients after 5 years, as well as a trend toward decreased all-cause mortality [121]. Large, randomised, controlled trials are required to assess whether treatment of OSA can reduce CHD morbidity. Recent randomised controlled studies looked at the overall cardiovascular morbidity [122]. In the study by BARBÉ et al. [122], patients were allocated to receive CPAP treatment or no active intervention. The main outcome was the incidence of either systemic hypertension or cardiovascular events (nonfatal myocardial infarction, nonfatal stroke, transient ischaemic attack, hospitalisation for unstable angina or arrhythmia, heart failure or cardiovascular death). There was no benefit in intention-to-treat analysis. CPAP compared with usual care did not result in a statistically significant reduction in the incidence of hypertension or cardiovascular events. Only in those using CPAP for $>4$ hours per night was there an improvement evidenced in per protocol analysis [122]. Large randomised controlled trials and long-term follow-up are needed. This is, for instance, the rationale of the Sleep Apnoea Cardiovascular End-points (SAVE) trial, an international secondary prevention treatment trial designed to include 5000 subjects [123].

Key findings and practical points

Studies in both clinical and general population cohorts have suggested an association between OSA and CAD. OSA has been found to be an independent predictor of incident CAD, at least before the age of 70 years. OSA is associated with an increased risk of cardiovascular mortality in CAD patients. Both retrospective and uncontrolled studies suggest a reduction in mortality in CHD patients when treating OSA. In large randomised controlled trials there is a reduction in the incidence of both hypertension and cardiovascular events in per protocol analysis only when CPAP treatment exceeds 4 hours per day. This strongly suggests, as in other clinical fields in OSA, that CPAP duration is critical. It should be increased above $5 \mathrm{~h}$ if feasible. This appears to be the lowest threshold required for improving daytime functioning, blood pressure and cardiovascular morbidity. 

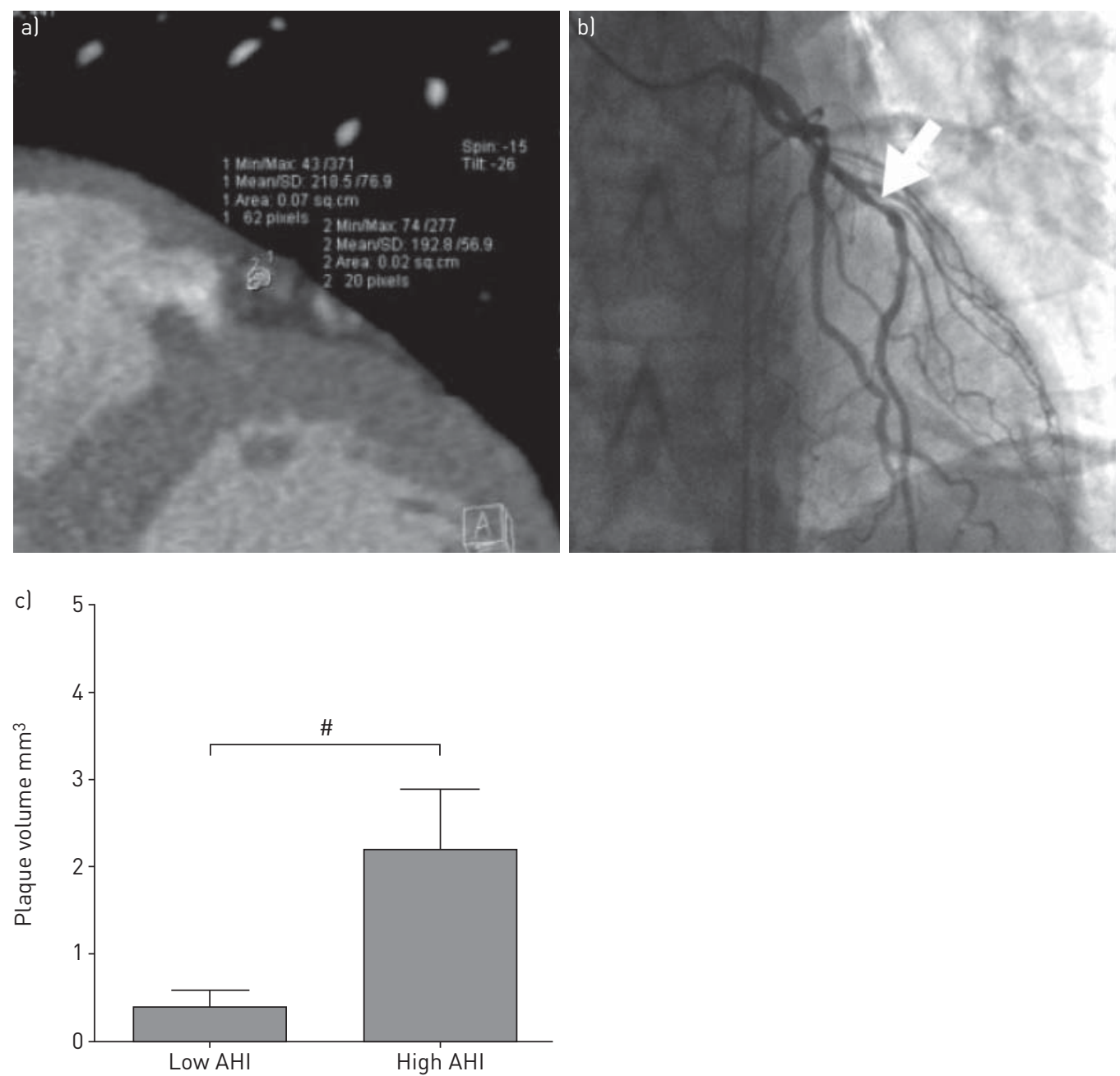

FIGURE 3 Severity of obstructive sleep apnoea predicts coronary artery plaque burden. a) Coronary computed tomography angiography showing calculation of the plaque volume. b) Invasive coronary angiogram of the same patient confirming obstructive distal left anterior descending coronary artery stenosis (arrow). c) Mean plaque volume in subjects with low and high apnoea/hypopnoea index (AHI). The two groups are otherwise comparable for demographics, symptoms, comorbidities and cardiovascular risks. ${ }^{*}: \mathrm{p}=0.017$. Reproduced from [119] with permission.

\section{SDB and heart failure: cause or effect?}

Heart failure represents a clinical phenotype resulting from acute or chronic development of cardiac and extra-cardiac diseases. Hypertension, cardiomyopathies, including CAD, and valvulopathies are common cardiac causes of heart failure, while clinical conditions such as kidney dysfunction, widespread atherosclerosis, diabetes mellitus, and lung and thyroid gland diseases could also favour the development of cardiac dysfunction. A characteristic feature of heart failure is its association with neurohumoral activation and, in particular, with increased sympathetic activity. The clinical manifestations of heart failure could vary from a largely asymptomatic state to a variable combination of symptoms of varying intensity. The prevalence of heart failure may vary from $\sim 1 \%$ in subjects aged $45-54$ years to $>10 \%$ in subjects aged $>75$ years [124], with a progressive increase in frequency for each decade after 50 years of age [125]. Moreover, due to the progressive increase in population age and the improved management of acute cardiac events, the prevalence of heart failure is expected to increase by $25 \%$ over the next 20 years, thus representing an important healthcare problem, especially in the elderly, because of its association with low quality of life, high cost of medical supplies and poor prognosis [126].

OSA phenotype is strongly associated with obesity, while CSA-CSR is rather confined to normal and underweight patients. Finally, although OSA is associated with the whole spectrum of cardiovascular morbidities including heart failure, CSA-CSR is either associated with heart failure or may be a consequence of stroke $[127,128]$. Thus, we examine the different interactions between heart failure and sleep apnoea in a 
bidirectional way to qualitatively evaluate whether either morbid condition qualifies as "cause" or "effect" in this relationship.

\section{Pathophysiological aspects \\ From OSA to HF}

Each obstructive respiratory event is associated with an increase of the negative intrathoracic pressure up to 60-70 $\mathrm{cmH}_{2} \mathrm{O}$ [129]. Also, hypoxic pulmonary vasoconstriction further aggravates cardiac haemodynamics in OSA. More specifically, augmented venous return (right ventricle preload) is associated with increased resistance to outflow (afterload) of the right ventricle. Decreased return to the left ventricle through pulmonary veins, together with a shift of interventricular septum leftward, impairs left ventricular filling resulting in decreased left ventricular preload. Finally, transmural systolic pressure of left ventricle and left ventricular afterload are also increased. This haemodynamic mismatch is repeated many times during the night-time over several years in OSA patients and its detrimental effect on myocardium is accompanied by additional adverse haemodynamic phenomena driven by the consequences of episodic hypoxia and hypercapnia in the context of increased sympathetic firing. All these haemodynamic effects are associated with increased myocardial oxygen consumption and myocardial ischaemia that in turn deteriorates cardiac function. Increased intrathoracic pressure could also result in increased pressure at the level of renal veins and subsequently in increased intra-glomerular pressure at kidney level. Finally, in patients with OSA, repetitive intrathoracic pressure swings might be detrimental for kidney haemodynamics (increased intraglomerular pressure variability), with potentially detrimental consequences for cardiac function, at least in the long-term. This mechanism could enhance renin-angiotensin system activity beyond increased sympathetic firing at kidney level [130].

Disproportionate sympathetic activation in patients with OSA extends well beyond sleep time, with detrimental effects on cardio-renal haemodynamics during the entire day [35]. Increased peripheral vascular resistance and impaired sodium handling are important pathophysiological levers of increased cardiac workload which may precipitate the occurrence of heart failure [131]. As previously mentioned, there is also low-grade inflammation, oxidative stress and endothelial dysfunction that may be related to sleep apnoea, obesity or a combination of both and can also contribute to heart failure occurrence. Taking all these observations together, it could be concluded that OSA promotes subclinical organ damage and that heart failure could develop later during follow-up, due to the above pathophysiological mechanisms, and also as a consequence of evolving coronary disease [17].

\section{From HF to OSA}

Reduced stroke volume is associated with fluid retention in patients with heart failure, and impaired kidney function contributes to this phenomenon. Fluids are redistributed during recumbent sleep with a nocturnal fluid shift to the rostral sections of subjects' body [130]. As a consequence, peri-pharyngeal oedema could occur, aggravating upper airflow dynamics and facilitating pharyngeal collapse. It has been also demonstrated that the greater the leg oedema during the day, the higher the upper airway propensity to collapse, while sedentary life might be a significant modulator of this association in heart failure patients [132].

\section{From CSA-Cheyne-Stokes respiration to HF}

Repetitive arousals from sleep in patients with CSA-Cheyne-Stokes respiration (CSR) promote sympathetic activation with consequent deterioration of systemic and renal haemodynamics (i.e. generalised vasoconstriction and increased tubular sodium reabsorption). Additionally, increased cardiac workload as a function of increased blood pressure and heart rate may contribute to myocardial ischaemia. In CSACSR, the upper airway is usually not collapsed, at least in early heart failure stages. It was also recently reported that stroke volume in heart failure patients with CSA-CSR is less impaired compared to patients with OSA, suggesting that fluid retention is less pronounced in CSA-CSR [133].

\section{From HF to CSA-CSR}

In CSA-CSR, increased left ventricular filling pressure and volume overload are associated with pulmonary congestion and activation of parasympathetic afferent drive to respiratory centres that, together with central and peripheral chemoreflex overactivity, promote hyperventilation triggered by reflex enhancement of central sympathetic drive [130]. Reactive hyperventilation reduces carbon dioxide partial concentration below the apnoeic threshold, i.e. the carbon dioxide partial pressure below which respiratory activity is suppressed [128]. The hypocapnia mediated breathing cessation, i.e. a central apnoea, terminates when metabolic carbon dioxide augments over the apnoeic threshold, which in turn causes hyperventilation accompanied by a subsequent reduction in carbon dioxide concentration below the apnoeic threshold. This cyclic phenomenon is perpetuated until therapeutic measures to avoid hypocapnia are administered. In heart failure patients, effective circulation time is increased due to reduced stroke volume and pulmonary 
stasis, functional residual capacity is decreased due to pleural effusions and pulmonary stasis, and both hypercapnic and hypoxic ventilatory responses are usually increased. All these conditions may initiate or accentuate CSA-CSR [128].

\section{Epidemiological aspects}

From OSA to HF

Cross-sectional data from the Sleep Heart Health study in 4442 patients (mean age 62 years, males 44\%) demonstrated that the adjusted risk of prevalent self-reported heart failure in patients with OSA (AHI $>10)$ was almost 2.4 times higher compared to patients with AHI $\leqslant 10$ [118]. Prospective data [17] from the same cohort (mean follow-up 8.7 years) showed that patients without self-reported heart failure at baseline and $\mathrm{AHI}>30$ as compared to those with $\mathrm{AHI}<5$, had a $58 \%$ higher rate of incident heart failure during the follow-up period. Additionally for every 10-unit AHI increase, the incidence of heart failure augmented by $13 \%$, thus the higher the severity of OSA at baseline, the greater the incidence of heart failure. Finally, incident heart failure was associated with baseline OSA in males but not females. As previously mentioned, it is considered as a lack of power since the female population is poorly represented in the highest AHI tertiles in this particular cohort. Finally, severe OSA was associated with a 58\% increased risk of incident heart failure compared to subjects without sleep apnoea [17].

\section{From HF to OSA or CSA-CSR}

In different observational studies with almost 1000 heart failure patients (ejection fraction $<40-45 \%$ ) the prevalence of OSA ranges from $26 \%$ to $53 \%$, and for CSA-CSR from $15 \%$ to $39 \%$ [133]. However, in the study with the largest number of recruited heart failure patients $(n=700)$ [89], the prevalence of OSA and CSA-CSR was 36\% and 39\%, respectively. Also, it was observed that patients with CSA-CSR are more symptomatic and demonstrated a lower ejection fraction compared to those with OSA. These findings from observational cohorts suggest that $75 \%$ of HF patients with evident systolic dysfunction also had OSA or CSA [89, 134].

It has been questioned whether CSR-CSA is only a marker of congestive heart failure severity. However, CSR-CSA, independently of other risk factors, seems to increase the risk of mortality in congestive heart failure by two- to three-fold [135-137], although this is not confirmed in all studies [138]. One of the most convincing studies recruited 218 heart failure patients (mean age 56 years, mean ejection fraction 25\%) [139]. Untreated heart failure patients with mild or no OSA as compared to untreated patients with at least moderate OSA demonstrated $50 \%$ less incidence of fatal events $(12 \%$ versus $24 \%, \mathrm{p}=0.029)$.

In another observational study, 193 patients with ischaemic or not ischaemic aetiology of heart failure (ejection fraction of $\leqslant 45 \%$ ) were divided into those with at least moderate sleep apnoea (AHI $\geqslant 15)$ and in those with mild or no sleep apnoea $(\mathrm{AHI}<15)$ [140]. In the ischaemic heart failure group the presence of sleep apnoea was associated with adjusted three-fold increased mortality compared to those with AHI $<15$. By contrast, in the non-ischaemic heart failure group, prevalent sleep apnoea of at least moderate severity was not associated with different mortality rate compared to the subgroup of patients with mild or no sleep apnoea.

Also, a recent observational large-scale long-term study was conducted in heart failure patients (ejection fraction $<40 \%$ ) who already had an implanted cardiac resynchronisation device and cardioverter defibrillator [90]. All patients underwent polygraphy at baseline and received CPAP, ASV or no treatment for sleep apnoea. 32\% of patients were classified as having OSA, 34\% as having CSA and 34\% patients as having mild or no SDB. Those with at least moderate sleep apnoea received either CPAP or ASV and were observed for 4 years. The primary end-point was the event-free survival time to first appropriate cardioverter-defibrillator therapy. Both CSA and OSA were independently associated with a shorter eventfree survival time period, awaiting first monitored ventricular arrhythmia and appropriate cardioverterdefibrillator therapy.

While evidence may support the possibility of progression from OSA and CSA to heart failure, no data is available on the possibility that CSA might lead to heart failure development.

These data taken together suggest that diagnosis and treatment of OSA and CSR-CSA are mandatory. This is underlined in international guidelines mentioning a higher morbidity in heart failure patients presenting with sleep apnoea and recommending sleep apnoea specific treatment [141].

\section{Clinical aspects: effects of treatment}

From OSA to HF

The main question to address in this section is whether treatment of OSA is associated with ameliorated cardiac function and heart failure prognosis on top of the traditional treatment for heart failure. 
Continuous positive airway pressure

By using one night CPAP application in eight patients with heart failure (ejection fraction $<45 \%$ ), positive airway pressure effects on night-time changes in intrathoracic pressure and afterload levels were assessed [142]. Patients underwent assessment before sleep and during stage 2, 1 day before CPAP application, the day of CPAP application, and 1 day after CPAP application. Although afterload increased in all three nights in stage 2 compared to the pre-sleeping period, this increase was reduced by more than two-fold during CPAP application compared to pre-treatment and post-treatment nights. Additionally, the magnitude of negative intrathoracic pressure swings was found to be reduced by almost six-fold during the night of CPAP application compared to the previous night and by almost four-fold compared to the following night [142]. These physiological effects of CPAP may explain why randomised controlled studies demonstrated a significant improvement in left ventricular ejection fraction (LVEF) [143, 144]. It should be noted, however, that these studies had limited sample size and short duration of follow-up, i.e. maximum of 3 months. 24 severe heart failure patients were randomised to CPAP treatment and nonCPAP (controls) for 1 month [144]. Systolic blood pressure and heart rate decreased significantly in the CPAP group compared to baseline, while these measures did not change in the control group, suggesting that CPAP was beneficial in reducing workload of the left ventricle. Additionally, LVEF demonstrated a relative increase by $9 \%$ in the CPAP group compared to controls $(\mathrm{p}<0.001)$, with a within CPAP group ejection fraction of $35 \%$ (from $25 \%$ at baseline to $33.8 \%$ at 1 month). Several studies evidenced a reduction in sympathetic activity during CPAP treatment [145-147]. In a mid-term study (3 month) LVEF was found increased during CPAP when compared to baseline levels (from $37.6 \%$ to $42.6 \%$, $\mathrm{p}<0.001$ ), with a concomitant reduction in urinary norepinephrine [147]. Regarding long-term effects of CPAP on mortality, there are data suggesting an improvement. However, these data come from nonrandomised studies with small sample size [139]. Thus definite conclusions regarding the effects of CPAP on survival rate in heart failure patients cannot be raised. It emphasises the need of adequately powered randomised trials in order to further assess the impact of CPAP on the prognosis of heart failure patients with OSA, including intermediate clinical end-points.

From HF to OSA

The clinical question to be answered in this section is whether treatment of heart failure ameliorates OSA.

Drugs for heart failure

Pivotal symptomatic treatment of HF is based on use of diuretic agents. In a small uncontrolled shortterm interventional study [148], 15 patients with severe OSA and hypertensive aetiology of diastolic heart failure were hospitalised to receive furosemide $20 \mathrm{mg}$ and spironolactone $100 \mathrm{mg}$ twice daily for 3 days. Before and after the intervention, AHI by polysomnography and upper airway dimensions by acoustic pharyngometry were determined. Beyond the significant decrease in body size among participants, there was also a decrease in AHI by 17 events $\mathrm{h}^{-1}$, and an increase of oropharyngeal area by $55 \mathrm{~cm}^{2}$. This study confirm the plausible pathophysiological role of peri-pharyngeal oedema in the development of OSA in heart failure patients and also suggests that pharmacological treatment of heart failure with diuretics may reduce the severity of OSA, even when heart failure patients do not exhibit impaired systolic function and fluid retention. Patients with fluid retention and systolic heart failure could similarly benefit from diuretic agents. However, in the case of more severe heart failure with increased disease burden the effects of pharmacological treatment on OSA might be different (e.g. inappropriate reduction in left ventricle filling pressures).

Cardiac rehabilitation

Exercise rehabilitation programmes represent beneficial therapeutic measures to increase physical performance in patients with heart failure. A 4-month rehabilitation programme has been shown, for instance, to both improve OSA and significantly decrease muscle sympathetic nerve activity [149].

Atrial overdrive pacing

Although atrial overdrive pacing does not have a specific therapeutic position in the management of heart failure, it was hypothesised that suppressing the periods of bradycardia associated with apnoea may reduce autonomic imbalance in OSA. One of the hypotheses has been that reducing the variability in cardiac output with cardiac pacing may stabilise respiratory output, and possibly stabilise pharyngeal calibre, since upper airway calibre oscillates in synchrony with fluctuations in respiratory output [150]. This should also be put in the context of the high prevalence of OSA in patients with long-term pacing whatever the indication [151]. Despite a promising initial report that essentially included mild OSA and mild-tomoderate CSA-CSR evidencing a mild but significant effect [152], the following studies were mostly negative, suggesting that there is little effect of atrial pacing in OSA [106, 153-155]. 
Resynchronisation therapy

By increasing cardiac output in patients with heart failure and OSA, cardiac resynchronisation therapy could reduce fluid retention and oedema in peri-pharyngeal tissues. In a meta-analysis of three studies of patients with OSA [156], LVEF was increased over a follow-up period of 23 weeks but there was no significant change in AHI. Owing to the severity of heart failure, the increase in cardiac output could be insufficient to adequately counterbalance fluid retention.

\section{From CSA to HF}

The main question of the present section is whether treating CSA is associated with better prognosis in heart failure patients.

\section{Drugs}

Theophylline has a stimulating effect on the central nervous system, including respiratory drive. The hypothesis of whether theophylline might be accompanied by beneficial effects on both CSA and heart failure was examined previously in a double-blind, randomised placebo-controlled study [157]. Despite its efficacy on central events in this pilot study, the clinical data for long-term efficacy and safety remain rather limited. Moreover, a long-term drug-induced pro-arrhythmic effect should be excluded before any recommendation is provided.

Acetazolamide is a mild diuretic and also a drug stimulating the respiratory drive. It has been used as treatment for high altitude CSA-CSR and in subjects prone to mountain sickness. Recently, a double-blind, randomised trial in healthy subjects demonstrated that blood pressure increase after acute exposure at high altitude can be counteracted by acetazolamide [158]. In CSA-CSR, there have been also promising results. In 12 patients (mean age 66 years, 100\% males) with heart failure (ejection fraction 20\%) under stable haemodynamic conditions, acetazolamide was administered once daily $1 \mathrm{~h}$ before bedtime over 1 week [52]. AHI was reduced by $38 \%$ and central apnoeas by almost $50 \%$, with no significant impact on OSA. However, long-term safety and efficacy results in heart failure patients are lacking.

\section{Continuous positive airway pressure}

In patients with heart failure, the inspiratory muscles generate greater force per breath and systolic intrathoracic pressure contributes more to left ventricular transmural pressure than in healthy subjects. By increasing intra-thoracic pressure in patients with heart failure, CPAP unloads inspiratory muscles and reduces left ventricular afterload without compromising cardiac index [159, 160]. Finally, as previously mentioned, CPAP reduces the concentrations of nocturnal urinary and daytime plasma norepinephrine in heart failure patients presenting with CSA-CSR [145]. Thus, these promising results represent a plausible background from which to set randomised trials assessing the role of CPAP on CSA-CSR and heart failure prognosis in the long term.

An initial study assessing the prognostic role of CSA-CSR on the combined end-point of mortality and cardiac transplantation rate had limited sample size and did not reach statistical significance [161]. The Canadian Continuous Positive Airway Pressure for Patients with Central Sleep Apnoea and Heart Failure (CANPAP) trial [162] was thus designed as a multicentre, randomised, open-label blinded to the trial in order to investigate the following questions: 1) whether CPAP reduces the severity of CSA; 2) whether the potential reduction of CSA severity would be translated into better outcomes in terms of morbidity and mortality (i.e. transplantation-free survival); and 3) whether CPAP ameliorates cardiovascular parameters such as LVEF. Heart failure patients who were eligible to participate in the CANPAP trial were those in with a New York Heart Association class between II and IV, an ejection fraction $<40 \%$, and AHI $\geqslant 15 \%$ with $>50 \%$ of CSA phenomena. Patients (mean age 63 years, 97\% males, mean ejection fraction 24.5\%, AHI 40) were randomised to medical therapy alone $(n=130)$ or to CPAP in addition to medical therapy $(n=128)$. They were observed for a mean period of 2 years. CPAP treatment had to be applied for at least $6 \mathrm{~h}$ daily. After an initial 3-month CPAP titration period, the group of patients treated with the combined regimen of $\mathrm{CPAP}$ and medical therapy as compared to the group treated with medical therapy alone, demonstrated a greater reduction in the frequency of apnoea and hypopnoea episodes, as well as in norepinephine levels, while LVEF and exercise capacity, as assessed by the distance walked in $6 \mathrm{~min}$, were significantly increased in the former group as compared to the latter. By contrast, no difference in hospitalisations and in mortality rates were observed between the two groups. Interestingly, an initial divergence of the event-rates curve was observed in favour of the control group, suggesting that CPAP might have had an early adverse effect in some patients. Authors have also observed that the results of the "intention-to-treat analysis" were different from the "per-protocol analysis", since dropout patients demonstrated higher mortality rates than those of the remaining randomised patients. Another explanation for this "paradox" might be the adverse effect of 
the relatively rapid CPAP titration, especially in patients with low filling pressures and low stroke volume, because of more aggressive diuretic therapy in some patients [162].

A post hoc analysis of the CANPAP trial [163] reported a comparative evaluation of patients with AHI $<15$ at 3 month (suppressed CSA group); patients with AHI $\geqslant 15$ at 3 month (unsuppressed CSA group); and patients not receiving CPAP (control group). Heart transplantation-free survival rate was significantly better in the suppressed CSA-CSR group compared to controls $(\mathrm{p}=0.034)$, while no difference in the outcome rate was observed between the unsuppressed CSA-CSR group and controls. Of note, the adherence to treatment did not differ between the two subgroups "on CPAP" treatment, suggesting a possible lack of efficacy or that effective and prompt treatment could be important in this clinically fragile group of heart failure patients [163].

\section{Assisted servo-ventilation}

Treatment with CPAP improved cardiac function in heart failure patients with CSA by stabilising ventilation. Nevertheless, both efficacy in some patients and tolerance in others may limit CPAP use in heart failure. This is the reason why the new large trials are currently using ASV and not CPAP. ASV, a variable flow-targeted inspiratory pressure support, effectively suppresses CSA in heart failure patients [164] and is also well tolerated. When compared to sham ASV, ASV improved objective sleepiness and significantly reduced brain natriuretic peptide and urinary metadrenaline excretion levels in heart failure patients with CSA-CSR [165]. However, ASV did not increase LVEF. In a comparative study between CPAP and ASV with a follow-up of 6 months, only ASV resulted in a significant increase in LVEF and ASV efficacy and compliance was also better [166]. ASV is potentially the most effective and acceptable treatment for CSA-CSR in heart failure; two major studies have been designed and are currently ongoing, including $\sim \geqslant 1000$ patients. The first, the Serve Heart Failure study, has just completed its initial recruitment stage $(n=1325)$ [167]. These two studies, although not fully comparable with regard to patient selection, should allow determination of whether ASV is able to improve heart failure and reduce mortality.

\section{Phrenic nerve stimulation}

This technique was introduced to treat CSA-CSR in a small cohort of heart failure patients [168]. Through either the left or the right brachiocephalic vein or through the pericardiophrenic vein, an overnight transvenous catheter was introduced to deliver energy and periodically stimulate the phrenic nerve. AHI and the arousal index were strongly decreased during the night of phrenic nerve stimulation compared to the night before the procedure. However, long-term results of the technique, possible complications due to the invasive nature of the procedure, and long-term tolerability remain to be addressed. Also it is unknown whether the improvement of CSA-CSR will be accompanied by improvement of cardiac function parameters.

\section{From HF to CSA}

The question addressed in this section is whether treatment of HF is associated with decline of severity in CSA.

\section{Exercise rehabilitation}

There are conflicting results in this field. In a previously mentioned study, no significant impact was observed on CSA-CSR severity, sleep patterns and muscle sympathetic nerve activity in patients undergoing cardiac exercise rehabilitation [149]. In another small cohort of 18 patients with heart failure and CSA-CSR, 6-month aerobic exercise training was accompanied by increased exercise capacity and improvement in CSA-CSR (three-fold reduction of both AHI and number of central apnoeas compared to baseline levels) [169]. More studies are needed investigating CSA-CSR improvement in larger cohorts since cardiac rehabilitation in HF is associated with improvement in cardiac performance and reduction in pulmonary congestion.

\section{Atrial overdrive pacing}

Atrial overdrive pacing has been tested as a therapeutic option in patients with a permanent pacemaker in order to reduce the severity of CSA-CSR in heart failure. During CSA-CSR, there is parasympathetic activation associated with bradycardia, blood pressure reduction and increased heart rate variability. Reducing heart rate variability using atrial overdrive pacing may have a positive impact on CSA-CSR. In patients with heart failure and a permanent pacemaker a significant reduction in AHI was observed compared to baseline levels [152]. However, there is no study comparing atrial overdrive pacing and CPAP in heart failure patients presenting with CSA-CSR. Thus, more studies are needed to evaluate whether atrial overdrive pacing ameliorates CSA-CSR in HF patients, a potential future option reserved for patients with permanent pacemaker stimulation [170]. 


\section{Resynchronisation therapy}

A recent meta-analysis including studies with CSA-CSR reported a clear beneficial effect of resynchronisation therapy on CSA-CSR severity. There was a significant improvement in AHI with a parallel significant increase in LVEF [156]. The effect of atrial overdrive pacing in addition to resynchronisation therapy in sleep apnoea patients with predominant CSA demonstrated a trend toward statistically significant greater effects compared to resynchronisation alone [156, 170].

\section{Cardiac transplantation}

Restoring cardiac function with heart transplantation might change the clinical history of CSA-CSR. In a prospective controlled trial, 22 patients with final stages of heart failure scheduled for heart transplantation underwent polysomnography before and 6 months after surgery [171]. In those presenting with CSA-CSR before surgery, heart transplantation reduced the severity of sleep apnoea. However, sleep apnoea did not disappear despite normalisation of sympathetic activity. Also, the type of residual sleep apnoea after transplantation was not exclusively of central type and interestingly OSA was the predominant residual type of events in most patients after surgery.

Cause or effect between sleep apnoea and heart failure: cutting the Gordian knot

There is evidence in animal models that repeated occlusions of the upper airway leads to ventricular hypertrophy, myocardial ischaemia [172] and left ventricular failure. Several groups reported that prolonged intermittent hypoxia resulted in oxidative stress [173] and increased sensitivity to ischaemia at the heart level $[174,175]$. HIF-1 and the endothelin system have both been found to be critically involved in acute [22] and chronic [176] myocardial responses.

In human disease, there is plausible pathophysiological background (i.e. increased intra-thoracic pressure swings, hypoxic pulmonary vasoconstriction, cardiovascular haemodynamic adaptations, functional myocardial ischaemia, sympathetic over activity, kidney dysfunction, increased systemic inflammation and oxidative stress, endothelial damage and dysmetabolism) to suggest that OSA might be the "cause" and heart failure the "effect" in this complex relationship. There is also clinical evidence that OSA is a risk factor for heart failure [17]. Conversely, there is also increasing pathophysiological evidence [130] (reduced stroke volume, fluid redistribution from standing to the recumbent position [132], enhanced variability in cardiac output with destabilisation of respiratory output and possibly of pharyngeal calibre) suggesting that heart failure may precede OSA in many cases.

Regarding treatment of OSA, available data show that treating OSA potentially ameliorates clinically important intermediate cardiovascular end-points while, so far, no definitive conclusion can be drawn with respect to long-term prognosis.

In patients with heart failure and CSA-CSR, CPAP had a favourable effect on different cardiovascular risk surrogates including LVEF, whereas it failed to reduce event rate and mortality. Ongoing studies using assisted servo-ventilation will elucidate the exact benefit that might be expected in terms of survival [167].

Also, aiming to reduce the severity of CSA with different treatments of heart failure is promising but not definitive. Among heart failure treatments, resynchronisation therapy reduced the severity of CSA-CSR more effectively compared to other therapies. A semi-quantitative score grading the weight of evidence for all directions of "cause-effect" relationships between sleep apnoea and heart failure is reported in table 1. Currently, the available evidence suggests that heart failure can be considered as "cause" and sleep apnoea as "effect". Data in favour of an inverse relationship are significant but limited regarding OSA and almost absent in the case of CSA-CSR.

\section{Key findings and practical points}

Clinically, in heart failure OSA phenotype is still mainly associated with obesity, while CSA-CSR is more confined to normal and overweight patients. OSA is associated with the whole spectrum of cardiovascular morbidities including heart failure while CSA-CSR is mainly associated with heart failure. Incident heart failure is increased during follow-up, when OSA is present at baseline in the general population. In ischaemic heart failure, OSA is associated with a three-fold increased mortality compared to patients with mild or no OSA. Definite conclusions regarding the effects of CPAP on survival rate in heart failure patients presenting with OSA cannot be raised. There is a need for adequately powered randomised trials in order to further assess the impact of CPAP on the prognosis of heart failure patients with OSA, including intermediate clinical end-points.

Diagnosis and treatment of OSA in heart failure are recommended by international guidelines. Whether simplified techniques may be used for screening and diagnosis remains to be debated. Treatment of OSA in 
TABLE 1 Interaction between sleep apnoea and heart failure (HF): arbitrary score weighting the evidence for possible causeeffect relationships in different directions ${ }^{\#}$

\begin{tabular}{lccc}
$\begin{array}{l}\text { Suggested direction of causal } \\
\text { relationship }\end{array}$ & $\begin{array}{c}\text { Pathophysiological } \\
\text { evidence }\end{array}$ & $\begin{array}{c}\text { Epidemiological } \\
\text { evidence }\end{array}$ & $\begin{array}{c}\text { Clinical } \\
\text { evidence }\end{array}$ \\
\hline OSA to HF & 2 & 1 & 1 \\
HF to OSA & 3 & 3 & 1 \\
CSA to HF & 2 & 0 & 0 \\
HF to CSA & 3 & 3 & 0 \\
\hline
\end{tabular}

OSA: obstructive sleep apnoea; CSA: central sleep apnoea. " : there are no evidence-based data supporting this arbitrary score, which corresponds to expert opinions as summarised by the authors; ": the individual total of each row.

heart failure does not differ from usual OSA management apart from a careful cardiovascular evaluation at baseline and during follow-up, involving a cardiologist.

Treatment of CSA-CSR may significantly improve heart failure. Nevertheless, CPAP trials (i.e. the CANPAP trial) have failed to demonstrate a significant improvement in mortality although post hoc analysis suggested that it might be the case when CSA-CSR is effectively suppressed. Large randomised trials to assess assisted servo-ventilation effects on CSA-CSR and HF morbidity and mortality are ongoing. Treatment of CSA-CSR should be started cautiously checking for possible haemodynamic changes during positive airway treatment.

\section{Conclusions}

There is evidence that sleep apnoea, presumably mainly through intermittent hypoxia, is associated with oxidative stress, systemic inflammation, vascular endothelium damage and dysfunction. Both systemic inflammation and endothelial dysfunction are aggravated when SDB is associated with other comorbid conditions such as morbid obesity. Sleep apnoea is identified as being part of the cluster of chronic metabolic disorders linked to obesity and associated with low-grade inflammation. There is also strong evidence supporting the association between sleep apnoea and heart failure, stroke, arrhythmias and CHD, as well as overall cardiovascular mortality. Finally, OSA is associated with heart failure in a bidirectional relationship while CSR-CSA is a breathing disorder seen in $>30 \%$ of patients with advanced congestive heart failure. The therapeutic implications of treating SDB in heart failure patients and treating heart failure in patients with CSR-CSA, e.g. using resynchronisation therapy, remain to be fully elucidated. Ongoing large randomized control trials may provide part of the answer.

\section{Acknowledgements}

The authors acknowledge the contribution provided by C. Lombardi in the preparation of this article.

\section{References}

1 Kapur VK, Baldwin CM, Resnick HE, et al. Sleepiness in patients with moderate to severe sleep-disordered breathing. Sleep 2005; 28: 472-477.

2 Canessa N, Castronovo V, Cappa SF, et al. Obstructive sleep apnea: brain structural changes and neurocognitive function before and after treatment. Am J Respir Crit Care Med 2011; 183: 1419-1426.

3 McNicholas WT, Bonsignore MR. Sleep apnoea as an independent risk factor for cardiovascular disease: Current evidence, basic mechanisms and research priorities. Eur Respir J 2007; 29: 156-178.

4 Levy P, Bonsignore MR, Eckel J. Sleep, sleep-disordered breathing and metabolic consequences. Eur Respir J 2009; 34: $243-260$.

5 Punjabi NM, Caffo BS, Goodwin JL, et al. Sleep-disordered breathing and mortality: a prospective cohort study. PLoS Med 2009; 6: e1000132.

6 Marin JM, Carrizo SJ, Vicente E, et al. Long-term cardiovascular outcomes in men with obstructive sleep apnoeahypopnoea with or without treatment with continuous positive airway pressure: an observational study. Lancet 2005; 365: 1046-1053.

7 Baguet JP, Barone-Rochette G, Tamisier R, et al. Mechanisms of cardiac dysfunction in obstructive sleep apnea. Nat Rev Cardiol 2012; 9: 679-688.

8 Peppard PE, Young T, Palta M, et al. Prospective study of the association between sleep-disordered breathing and hypertension. N Engl J Med 2000; 342: 1378-1384.

9 Parati G, Lombardi C, Hedner J, et al. Recommendations for the management of patients with obstructive sleep apnoea and hypertension. Eur Respir J 2013; 41: 523-538.

10 Peker Y, Kraiczi H, Hedner J, et al. An independent association between obstructive sleep apnoea and coronary artery disease. Eur Respir J 1999; 14: 179-184.

11 Arzt M, Young T, Finn L, et al. Association of sleep-disordered breathing and the occurrence of stroke. Am J Respir Crit Care Med 2005; 172: 1447-1451 
Mehra R, Benjamin EJ, Shahar E, et al. Association of nocturnal arrhythmias with sleep-disordered breathing: the Sleep Heart Health Study. Am J Respir Crit Care Med 2006; 173: 910-916.

13 Gami AS, Pressman G, Caples SM, et al. Association of atrial fibrillation and obstructive sleep apnea. Circulation 2004; 110: 364-367.

14 Monahan K, Storfer-Isser A, Mehra R, et al. Triggering of nocturnal arrhythmias by sleep-disordered breathing events. J Am Coll Cardiol 2009; 54: 1797-1804.

15 Young T, Finn L, Peppard PE, et al. Sleep disordered breathing and mortality: eighteen-year follow-up of the Wisconsin sleep cohort. Sleep 2008; 31: 1071-1078.

16 Lavie P, Lavie L. Unexpected survival advantage in elderly people with moderate sleep apnoea. J Sleep Res 2009; 18: 397-403.

17 Gottlieb DJ, Yenokyan G, Newman AB, et al. Prospective study of obstructive sleep apnea and incident coronary heart disease and heart failure: the Sleep Heart Health Study. Circulation 2010; 122: 352-360.

18 Chami HA, Resnick HE, Quan SF, et al. Association of incident cardiovascular disease with progression of sleepdisordered breathing. Circulation 2011; 123: 1280-1286.

19 Ryan S, Taylor CT, McNicholas WT. Systemic inflammation: a key factor in the pathogenesis of cardiovascular complications in obstructive sleep apnoea syndrome? Thorax 2009; 64: 631-636.

20 Chamberlin NL, Ling L. The effect of intermittent hypoxia on obstructive sleep apnea: beneficial or detrimental? J Appl Physiol 2011; 110: 9-10.

21 Gerst DG 3rd, Yokhana SS, Carney LM, et al. The hypoxic ventilatory response and ventilatory long-term facilitation are altered by time of day and repeated daily exposure to intermittent hypoxia. J Appl Physiol 2011; 110: 15-28.

22 Yokhana SS, Gerst DG 3rd, Lee DS, et al. Impact of repeated daily exposure to intermittent hypoxia and mild sustained hypercapnia on apnea severity. J Appl Physiol 2012; 112: 367-377.

23 Beguin PC, Belaidi E, Godin-Ribuot D, et al. Intermittent hypoxia-induced delayed cardioprotection is mediated by PKC and triggered by p38 map kinase and ERK1/2. J Mol Cell Cardiol 2007; 42: 343-351.

24 Belaidi E, Beguin PC, Levy P, et al. Prevention of HIF-1 activation and iNOS gene targeting by low-dose cadmium results in loss of myocardial hypoxic preconditioning in the rat. Am J Physiol Heart Circ Physiol 2008; 294: H901-H908.

25 Dematteis M, Godin-Ribuot D, Arnaud C, et al. Cardiovascular consequences of sleep-disordered breathing: contribution of animal models to understanding the human disease. ILAR J 2009; 50: 262-281.

26 Lavie L, Lavie P. Coronary collateral circulation in sleep apnea: a cardioprotective mechanism? Chest 2010; 137: 511-512.

27 Berger S, Aronson D, Lavie P, et al. Endothelial progenitor cells in acute myocardial infarction and sleep-disordered breathing. Am J Respir Crit Care Med 2013; 187: 90-98.

28 Fletcher EC, Miller J, Schaaf JW, et al. Urinary catecholamines before and after tracheostomy in patients with obstructive sleep apnea and hypertension. Sleep 1987; 10: 35-44.

29 Dimsdale JE, Coy T, Ziegler MG, et al. The effect of sleep apnea on plasma and urinary catecholamines. Sleep 1995; 18: 377-381.

30 Elmasry A, Lindberg E, Hedner J, et al. Obstructive sleep apnoea and urine catecholamines in hypertensive males: a population-based study. Eur Respir J 2002; 19: 511-517.

31 Hedner J, Darpo B, Ejnell H, et al. Reduction in sympathetic activity after long-term cpap treatment in sleep apnoea: cardiovascular implications. Eur Respir J 1995; 8: 222-229.

32 Ziegler MG, Mills PJ, Loredo JS, et al. Effect of continuous positive airway pressure and placebo treatment on sympathetic nervous activity in patients with obstructive sleep apnea. Chest 2001; 120: 887-893.

33 Somers VK, Dyken ME, Clary MP, et al. Sympathetic neural mechanisms in obstructive sleep apnea. J Clin Invest 1995; 96: 1897-1904.

34 Carlson JT, Hedner J, Elam M, et al. Augmented resting sympathetic activity in awake patients with obstructive sleep apnea. Chest 1993; 103: 1763-1768.

35 Narkiewicz K, Kato M, Phillips BG, et al. Nocturnal continuous positive airway pressure decreases daytime sympathetic traffic in obstructive sleep apnea. Circulation 1999; 100: 2332-2335.

36 Brooks D, Horner RL, Kozar LF, et al. Obstructive sleep apnea as a cause of systemic hypertension. Evidence from a canine model. J Clin Invest 1997; 99: 106-109.

37 Fletcher EC, Lesske J, Qian W, et al. Repetitive, episodic hypoxia causes diurnal elevation of blood pressure in rats. Hypertension 1992; 19: 555-561.

38 Bao G, Metreveli N, Li R, et al. Blood pressure response to chronic episodic hypoxia: Role of the sympathetic nervous system. J Appl Physiol 1997; 83: 95-101.

39 Fletcher EC, Bao G, Li R. Renin activity and blood pressure in response to chronic episodic hypoxia. Hypertension 1999; 34: 309-314.

40 Fletcher EC, Lesske J, Culman J, et al. Sympathetic denervation blocks blood pressure elevation in episodic hypoxia. Hypertension 1992; 20: 612-619.

41 Tamisier R, Pepin JL, Remy J, et al. 14 nights of intermittent hypoxia elevate daytime blood pressure and sympathetic activity in healthy humans. Eur Respir J 2011; 37: 119-128.

42 Narkiewicz K, van de Borne PJ, Pesek CA, et al. Selective potentiation of peripheral chemoreflex sensitivity in obstructive sleep apnea. Circulation 1999; 99: 1183-1189.

43 Bonsignore MR, Parati G, Insalaco G, et al. Continuous positive airway pressure treatment improves baroreflex control of heart rate during sleep in severe obstructive sleep apnea syndrome. Am J Respir Crit Care Med 2002; 166: 279-286.

44 Carlson JT, Hedner JA, Sellgren J, et al. Depressed baroreflex sensitivity in patients with obstructive sleep apnea. Am J Respir Crit Care Med 1996; 154: 1490-1496.

45 Ryan S, Ward S, Heneghan C, et al. Predictors of decreased spontaneous baroreflex sensitivity in obstructive sleep apnea syndrome. Chest 2007; 131: 1100-1107.

46 Baguet JP, Hammer L, Levy P, et al. The severity of oxygen desaturation is predictive of carotid wall thickening and plaque occurrence. Chest 2005; 128: 3407-3412.

47 Drager LF, Bortolotto LA, Lorenzi MC, et al. Early signs of atherosclerosis in obstructive sleep apnea. Am J Respir Crit Care Med 2005; 172: 613-618. 
48 Ip MS, Tse HF, Lam B, et al. Endothelial function in obstructive sleep apnea and response to treatment. Am J Respir Crit Care Med 2004; 169: 348-353.

49 Kohler M, Stoewhas AC, Ayers L, et al. Effects of continuous positive airway pressure therapy withdrawal in patients with obstructive sleep apnea: a randomized controlled trial. Am J Respir Crit Care Med 2011; 184: 1192-1199.

50 Nieto FJ, Herrington DM, Redline S, et al. Sleep apnea and markers of vascular endothelial function in a large community sample of older adults. Am J Respir Crit Care Med 2004; 169: 354-360.

51 Reichmuth KJ, Dopp JM, Barczi SR, et al. Impaired vascular regulation in patients with obstructive sleep apnea: effects of continuous positive airway pressure treatment. Am J Respir Crit Care Med 2009; 180: 1143-1150.

52 Saletu M, Nosiska D, Kapfhammer G, et al. Structural and serum surrogate markers of cerebrovascular disease in obstructive sleep apnea (OSA): association of mild OSA with early atherosclerosis. J Neurol 2006; 253: 746-752.

53 Savransky V, Nanayakkara A, Li J, et al. Chronic intermittent hypoxia induces atherosclerosis. Am J Respir Crit Care Med 2007; 175: 1290-1297.

54 Jun J, Reinke C, Bedja D, et al. Effect of intermittent hypoxia on atherosclerosis in apolipoprotein E-deficient mice. Atherosclerosis 2010; 209: 381-386.

55 Arnaud C, Poulain L, Levy P, et al. Inflammation contributes to the atherogenic role of intermittent hypoxia in apolipoprotein-E knock out mice. Atherosclerosis 2011; 219: 425-431.

56 Dematteis M, Julien C, Guillermet C, et al. Intermittent hypoxia induces early functional cardiovascular remodeling in mice. Am J Respir Crit Care Med 2008; 177: 227-235.

57 Arnaud C, Beguin PC, Lantuejoul S, et al. The inflammatory pre-atherosclerotic remodeling induced by intermittent hypoxia is attenuated by rantes/ccl5 inhibition. Am J Respir Crit Care Med 2011; 184: 724-731.

58 Libby P. Inflammation in atherosclerosis. Nature 2002; 420: 868-874.

59 Dyugovskaya L, Lavie P, Lavie L. Increased adhesion molecules expression and production of reactive oxygen species in leukocytes of sleep apnea patients. Am J Respir Crit Care Med 2002; 165: 934-939.

60 Dyugovskaya L, Lavie P, Lavie L. Phenotypic and functional characterization of blood gammadelta T cells in sleep apnea. Am J Respir Crit Care Med 2003; 168: 242-249.

61 Greenberg H, Ye X, Wilson D, et al. Chronic intermittent hypoxia activates nuclear factor-kappab in cardiovascular tissues in vivo. Biochem Biophys Res Commun 2006; 343: 591-596.

62 Yamauchi M, Tamaki S, Tomoda K, et al. Evidence for activation of nuclear factor $\kappa \mathrm{B}$ in obstructive sleep apnea. Sleep Breath 2006; 10: 189-193.

63 Ryan S, Taylor CT, McNicholas WT. Selective activation of inflammatory pathways by intermittent hypoxia in obstructive sleep apnea syndrome. Circulation 2005; 112: 2660-2667.

64 Ohga E, Nagase T, Tomita T, et al. Increased levels of circulating ICAM-1, VCAM-1, and L-selectin in obstructive sleep apnea syndrome. J Appl Physiol 1999; 87: 10-14.

65 Ryan S, Taylor CT, McNicholas WT. Predictors of elevated nuclear factor- $\kappa B$-dependent genes in obstructive sleep apnea syndrome. Am J Respir Crit Care Med 2006; 174: 824-830.

66 Barcelo A, Miralles C, Barbe F, et al. Abnormal lipid peroxidation in patients with sleep apnoea. Eur Respir J 2000; 16: 644-647.

67 Lavie L, Vishnevsky A, Lavie P. Evidence for lipid peroxidation in obstructive sleep apnea. Sleep 2004; 27: 123-128.

68 Chen L, Einbinder E, Zhang Q, et al. Oxidative stress and left ventricular function with chronic intermittent hypoxia in rats. Am J Respir Crit Care Med 2005; 172: 915-920.

69 Grebe M, Eisele HJ, Weissmann N, et al. Antioxidant vitamin c improves endothelial function in obstructive sleep apnea. Am J Respir Crit Care Med 2006; 173: 897-901.

70 Jelic S, Padeletti M, Kawut SM, et al. Inflammation, oxidative stress, and repair capacity of the vascular endothelium in obstructive sleep apnea. Circulation 2008; 117: 2270-2278.

71 Lonn E, Bosch J, Yusuf S, et al. Effects of long-term vitamin E supplementation on cardiovascular events and cancer: a randomized controlled trial. JAMA 2005; 293: 1338-1347.

72 Reichmuth KJ, Austin D, Skatrud JB, et al. Association of sleep apnea and type II diabetes: a population-based study. Am J Respir Crit Care Med 2005; 172: 1590-1595.

73 Priou P, Le Vaillant M, Meslier N, et al. Independent association between obstructive sleep apnea severity and glycated hemoglobin in adults without diabetes. Diabetes care 2012; 35: 1902-1906.

74 Punjabi NM, Shahar E, Redline S, et al. Sleep-disordered breathing, glucose intolerance, and insulin resistance: the Sleep Heart Health Study. Am J Epidemiol 2004; 160: 521-530.

75 Theorell-Haglow J, Berne C, Janson C, et al. Obstructive sleep apnoea is associated with decreased insulin sensitivity in females. Eur Respir J 2008; 31: 1054-1060.

76 Drager LF, Li J, Reinke C, et al. Intermittent hypoxia exacerbates metabolic effects of diet-induced obesity. Obesity 2011; 19: 2167-2174.

77 Polotsky VY, Li J, Punjabi NM, et al. Intermittent hypoxia increases insulin resistance in genetically obese mice. J Physiol 2003; 552: 253-264.

78 Coughlin SR, Mawdsley L, Mugarza JA, et al. Cardiovascular and metabolic effects of CPAP in obese males with OSA. Eur Respir J 2007; 29: 720-727.

79 West SD, Nicoll DJ, Wallace TM, et al. Effect of CPAP on insulin resistance and HbAlc in men with obstructive sleep apnoea and type 2 diabetes. Thorax 2007; 62: 969-974.

80 Hoyos CM, Killick R, Yee BJ, et al. Cardiometabolic changes after continuous positive airway pressure for obstructive sleep apnoea: a randomised sham-controlled study. Thorax 2012; 67: 1081-1089.

81 Sharma SK, Agrawal S, Damodaran D, et al. CPAP for the metabolic syndrome in patients with obstructive sleep apnea. N Engl J Med 2011; 365: 2277-2286.

82 Schahin SP, Nechanitzky T, Dittel C, et al. Long-term improvement of insulin sensitivity during cpap therapy in the obstructive sleep apnoea syndrome. Med Sci Monit 2008; 14: CR117-CR121.

83 Pepin JL, Tamisier R, Levy P. Obstructive sleep apnoea and metabolic syndrome: put CPAP efficacy in a more realistic perspective. Thorax 2012; 67: 1025-1027.

84 Newman AB, Nieto FJ, Guidry U, et al. Relation of sleep-disordered breathing to cardiovascular disease risk factors: the Sleep Heart Health Study. Am J Epidemiol 2001; 154: 50-59.

85 Tsioufis C, Thomopoulos K, Dimitriadis K, et al. The incremental effect of obstructive sleep apnoea syndrome on arterial stiffness in newly diagnosed essential hypertensive subjects. J Hypertens 2007; 25: 141-146. 
86 Robinson GV, Pepperell JC, Segal HC, et al. Circulating cardiovascular risk factors in obstructive sleep apnoea: data from randomised controlled trials. Thorax 2004; 59: 777-782.

87 Li J, Savransky V, Nanayakkara A, et al. Hyperlipidemia and lipid peroxidation are dependent on the severity of chronic intermittent hypoxia. J Appl Physiol 2007; 102: 557-563.

88 Lown B, Tykocinski M, Garfein A, et al. Sleep and ventricular premature beats. Circulation 1973; 48: 691-701.

89 Oldenburg O, Lamp B, Faber L, et al. Sleep-disordered breathing in patients with symptomatic heart failure: a contemporary study of prevalence in and characteristics of 700 patients. Eur J Heart Fail 2007; 9: 251-257.

90 Bitter T, Westerheide N, Prinz C, et al. Cheyne-Stokes respiration and obstructive sleep apnoea are independent risk factors for malignant ventricular arrhythmias requiring appropriate cardioverter-defibrillator therapies in patients with congestive heart failure. Eur Heart J 2011; 32: 61-74.

91 Bitter T, Gutleben K-J, Nölker G, et al. Treatment of Cheyne-Stokes respiration reduces arrhythmic events in chronic heart failure. J Cardiovasc Electrophysiol 2013; [in press DOI: 10.1111/jce.12197].

92 Wilke T, Groth A, Mueller S, et al. Incidence and prevalence of atrial fibrillation: an analysis based on 8.3 million patients. Europace 2013; 15: 486-493.

93 Mitchell AR, Spurrell PA, Sulke N. Circadian variation of arrhythmia onset patterns in patients with persistent atrial fibrillation. Am Heart J 2003; 146: 902-907.

94 Healey JS, Connolly SJ, Gold MR, et al. Subclinical atrial fibrillation and the risk of stroke. N Engl J Med 2012; 366: $120-129$.

95 Benjamin EJ, Wolf PA, D'Agostino RB, et al. Impact of atrial fibrillation on the risk of death: the Framingham Heart Study. Circulation 1998; 98: 946-952.

96 McManus DD, Hsu G, Sung SH, et al. Atrial fibrillation and outcomes in heart failure with preserved versus reduced left ventricular ejection fraction. J Am Heart Assoc 2013; 2: e005694.

97 Bitter T, Langer C, Vogt J, et al. Sleep-disordered breathing in patients with atrial fibrillation and normal systolic left ventricular function. Dtsch Arztebl Int 2009; 106: 164-170.

98 Drager LF, Bortolotto LA, Pedrosa RP, et al. Left atrial diameter is independently associated with arterial stiffness in patients with obstructive sleep apnea: potential implications for atrial fibrillation. Int J Cardiol 2010; 144: 257-259.

99 Maeno KI, Kasai T, Kasagi S, et al. Relationship between atrial conduction delay and obstructive sleep apnea. Heart Vessels 2012 [in press DOI: 10.1007/s00380-012-0288-8].

100 Lim HE, Kim YH, Kim SH, et al. Impact of obstructive sleep apnea on the atrial electromechanical activation time. Circ J 2009; 73: 249-255.

101 Dimitri H, Ng M, Brooks AG, et al. Atrial remodeling in obstructive sleep apnea: implications for atrial fibrillation. Heart Rhythm 2012; 9: 321-327.

102 Naruse Y, Tada H, Satoh M, et al. Concomitant obstructive sleep apnea increases the recurrence of atrial fibrillation following radiofrequency catheter ablation of atrial fibrillation: clinical impact of continuous positive airway pressure therapy. Heart Rhythm 2013; 10: 331-337.

103 Guilleminault C, Connolly SJ, Winkle RA. Cardiac arrhythmia and conduction disturbances during sleep in 400 patients with sleep apnea syndrome. Am J Cardiol 1983; 52: 490-494.

104 Simantirakis EN, Schiza SE, Chrysostomakis SI, et al. Atrial overdrive pacing for the obstructive sleep apneahypopnea syndrome. N Engl J Med 2005; 353: 2568-2577.

105 Kanagala R, Murali NS, Friedman PA, et al. Obstructive sleep apnea and the recurrence of atrial fibrillation. Circulation 2003; 107: 2589-2594.

106 Monahan K, Brewster J, Wang L, et al. Relation of the severity of obstructive sleep apnea in response to antiarrhythmic drugs in patients with atrial fibrillation or atrial flutter. Am J Cardiol 2012; 110: 369-372.

107 Matiello M, Nadal M, Tamborero D, et al. Low efficacy of atrial fibrillation ablation in severe obstructive sleep apnoea patients. Europace 2010; 12: 1084-1089.

108 Bitter T, Nolker G, Vogt J, et al. Predictors of recurrence in patients undergoing cryoballoon ablation for treatment of atrial fibrillation: the independent role of sleep-disordered breathing. J Cardiovasc Electrophysiol 2012; 23: 18-25.

109 Patel D, Mohanty P, Di Biase L, et al. Safety and efficacy of pulmonary vein antral isolation in patients with obstructive sleep apnea: the impact of continuous positive airway pressure. Circ Arrhythm Electrophysiol 2010; 3: $445-451$.

$110 \mathrm{Ng}$ CY, Liu T, Shehata M, et al. Meta-analysis of obstructive sleep apnea as predictor of atrial fibrillation recurrence after catheter ablation. Am J Cardiol 2011; 108: 47-51.

111 Bitter T, Westerheide N, Hossain SM, et al. Symptoms of sleep apnoea in chronic heart failure - results from a prospective cohort study in 1,500 patients. Sleep Breath 2012; 16: 781-791.

112 Calkins H, Kuck KH, Cappato R, et al. 2012 HRS/EHRA/ECAS expert consensus statement on catheter and surgical ablation of atrial fibrillation: recommendations for patient selection, procedural techniques, patient management and follow-up, definitions, endpoints, and research trial design. Heart Rhythm 2012; 9: 632-696.

113 Echt DS, Liebson PR, Mitchell LB, et al. Mortality and morbidity in patients receiving encainide, flecainide, or placebo. The cardiac arrhythmia suppression trial. N Engl J Med 1991; 324: 781-788.

114 Kiely JL, McNicholas WT. Cardiovascular risk factors in patients with obstructive sleep apnoea syndrome. Eur Respir J 2000; 16: 128-133.

115 Peker Y, Hedner J, Kraiczi H, et al. Respiratory disturbance index: an independent predictor of mortality in coronary artery disease. Am J Respir Crit Care Med 2000; 162: 81-86.

116 Peker Y, Carlson J, Hedner J. Increased incidence of coronary artery disease in sleep apnoea: a long-term follow-up. Eur Respir J 2006; 28: 596-602.

117 Nakashima H, Katayama T, Takagi C, et al. Obstructive sleep apnoea inhibits the recovery of left ventricular function in patients with acute myocardial infarction. Eur Heart J 2006; 27: 2317-2322.

118 Shahar E, Whitney CW, Redline S, et al. Sleep-disordered breathing and cardiovascular disease: Cross-sectional results of the sleep heart health study. Am J Respir Crit Care Med 2001; 163: 19-25.

119 Kent BD, Garvey JF, Ryan S, et al. Severity of obstructive sleep apnoea predicts coronary artery plaque burden: a coronary CT angiography study. Eur Respir J 2013 [in press DOI: 10.1183/09031936.00094812].

120 Milleron O, Pilliere R, Foucher A, et al. Benefits of obstructive sleep apnoea treatment in coronary artery disease: A long-term follow-up study. Eur Heart J 2004; 25: 728-734. 
121 Cassar A, Morgenthaler TI, Lennon RJ, et al. Treatment of obstructive sleep apnea is associated with decreased cardiac death after percutaneous coronary intervention. J Am Coll Cardiol 2007; 50: 1310-1314.

122 Barbé F, Duran-Cantolla J, Sanchez-de-la-Torre M, et al. Effect of continuous positive airway pressure on the incidence of hypertension and cardiovascular events in nonsleepy patients with obstructive sleep apnea: a randomized controlled trial. JAMA 2012; 307: 2161-2168.

123 McEvoy RD, Anderson CS, Antic NA, et al. The Sleep Apnea Cardiovascular Endpoints (SAVE) trial: rationale and start-up phase. J Thoracic Dis 2010; 2: 138-143.

124 Redfield MM, Jacobsen SJ, Burnett JC Jr, et al. Burden of systolic and diastolic ventricular dysfunction in the community: appreciating the scope of the heart failure epidemic. JAMA 2003; 289: 194-202.

125 Cowie MR, Wood DA, Coats AJS, et al. Incidence and aetiology of heart failure; a population-based study. Eur Heart J 1999; 20: 421-428.

126 Go AS, Mozaffarian D, Roger VL, et al. Heart disease and stroke statistics - 2013 update: a report from the American heart association. Circulation 2013; 127: e6-e245.

127 Sin DD, Fitzgerald F, Parker JD, et al. Risk factors for central and obstructive sleep apnea in 450 men and women with congestive heart failure. Am J Respir Crit Care Med 1999; 160: 1101-1106.

128 Pepin JL, Chouri-Pontarollo N, Tamisier R, et al. Cheyne-Stokes respiration with central sleep apnoea in chronic heart failure: proposals for a diagnostic and therapeutic strategy. Sleep Med Rev 2006; 10: 33-47.

129 Bradley TD, Floras JS. Obstructive sleep apnoea and its cardiovascular consequences. Lancet 2009; 373: 82-93.

130 Kasai T, Floras JS, Bradley TD. Sleep apnea and cardiovascular disease: a bidirectional relationship. Circulation 2012; 126: 1495-1510.

131 Kasai T, Arcand J, Allard JP, et al. Relationship between sodium intake and sleep apnea in patients with heart failure. J Am Coll Cardiol 2011; 58: 1970-1974.

132 Yumino D, Redolfi S, Ruttanaumpawan P, et al. Nocturnal rostral fluid shift: a unifying concept for the pathogenesis of obstructive and central sleep apnea in men with heart failure. Circulation 2010; 121: 1598-1605.

133 Yumino D, Kasai T, Kimmerly D, et al. Differing effects of obstructive and central sleep apneas on stroke volume in patients with heart failure. Am J Respir Crit Care Med 2013; 187: 433-438.

134 Lévy P, Pépin JL, Tamisier R, et al. Prevalence and impact of central sleep apnea in heart failure. Sleep Med Clin 2007; 2: 615-621.

135 Javaheri S, Shukla R, Zeigler H, et al. Central sleep apnea, right ventricular dysfunction, and low diastolic blood pressure are predictors of mortality in systolic heart failure. J Am Coll Cardiol 2007; 49: 2028-2034.

136 Hanly PJ, Zuberi-Khokhar NS. Increased mortality associated with Cheyne-Stokes respiration in patients with congestive heart failure. Am J Respir Crit Care Med 1996; 153: 272-276.

137 Lanfranchi PA, Braghiroli A, Bosimini E, et al. Prognostic value of nocturnal Cheyne-Stokes respiration in chronic heart failure. Circulation 1999; 99: 1435-1440.

138 Roebuck T, Solin P, Kaye DM, et al. Increased long-term mortality in heart failure due to sleep apnoea is not yet proven. Eur Respir J 2004; 23: 735-740.

139 Wang H, Parker JD, Newton GE, et al. Influence of obstructive sleep apnea on mortality in patients with heart failure. J Am Coll Cardiol 2007; 49: 1625-1631.

140 Yumino D, Wang H, Floras JS, et al. Relationship between sleep apnoea and mortality in patients with ischaemic heart failure. Heart 2009; 95: 819-824.

141 Dickstein K, Cohen-Solal A, Filippatos G, et al. ESC guidelines for the diagnosis and treatment of acute and chronic heart failure 2008 of the European Society of Cardiology. Developed in collaboration with the heart failure association of the ESC (HFA) and endorsed by the European Society of Intensive Care Medicine (ESICM). Eur Heart J 2008; 29: 2388-2442.

142 Tkacova R, Rankin F, Fitzgerald FS, et al. Effects of continuous positive airway pressure on obstructive sleep apnea and left ventricular afterload in patients with heart failure. Circulation 1998; 98: 2269-2275.

143 Mansfield DR, Gollogly NC, Kaye DM, et al. Controlled trial of continuous positive airway pressure in obstructive sleep apnea and heart failure. Am J Respir Crit Care Med 2004; 169: 361-366.

144 Kaneko Y, Floras JS, Usui K, et al. Cardiovascular effects of continuous positive airway pressure in patients with heart failure and obstructive sleep apnea. N Engl J Med 2003; 348: 1233-1241.

145 Naughton MT, Benard DC, Liu PP, et al. Effects of nasal CPAP on sympathetic activity in patients with heart failure and central sleep apnea. Am J Respir Crit Care Med 1995; 152: 473-479.

146 Kaye DM, Mansfield D, Aggarwal A, et al. Acute effects of continuous positive airway pressure on cardiac sympathetic tone in congestive heart failure. Circulation 2001; 103: 2336-2338.

147 Usui K, Bradley TD, Spaak J, et al. Inhibition of awake sympathetic nerve activity of heart failure patients with obstructive sleep apnea by nocturnal continuous positive airway pressure. J Am Coll Cardiol 2005; 45: 2008-2011.

148 Bucca CB, Brussino L, Battisti A, et al. Diuretics in obstructive sleep apnea with diastolic heart failure. Chest 2007; 132: $440-446$.

149 Ueno LM, Drager LF, Rodrigues AC, et al. Effects of exercise training in patients with chronic heart failure and sleep apnea. Sleep 2009; 32: 637-647.

150 Wellman A, Malhotra A, White DP. Atrial pacing in sleep apnea syndrome. N Engl J Med 2002; 347: 445-446.

151 Garrigue S, Pepin JL, Defaye P, et al. High prevalence of sleep apnea syndrome in patients with long-term pacing: the European Multicenter Polysomnographic Study. Circulation 2007; 115: 1703-1709.

152 Garrigue S, Bordier P, Jais P, et al. Benefit of atrial pacing in sleep apnea syndrome. N Engl J Med 2002; 346: 404-412.

153 Pepin JL, Defaye P, Garrigue S, et al. Overdrive atrial pacing does not improve obstructive sleep apnoea syndrome. Eur Respir J 2005; 25: 343-347.

154 Luthje L, Unterberg-Buchwald C, Dajani D, et al. Atrial overdrive pacing in patients with sleep apnea with implanted pacemaker. Am J Respir Crit Care Med 2005; 172: 118-122.

155 Krahn AD, Yee R, Erickson MK, et al. Physiologic pacing in patients with obstructive sleep apnea: a prospective, randomized crossover trial. J Am Coll Cardiol 2006; 47: 379-383.

156 Lamba J, Simpson CS, Redfearn DP, et al. Cardiac resynchronization therapy for the treatment of sleep apnoea: a meta-analysis. Europace 2011; 13: 1174-1179.

157 Javaheri S, Parker TJ, Wexler L, et al. Effect of theophylline on sleep-disordered breathing in heart failure. $N$ Engl $J$ Med 1996; 335: 562-567. 
158 Parati G, Revera M, Giuliano A, et al. Effects of acetazolamide on central blood pressure, peripheral blood pressure, and arterial distensibility at acute high altitude exposure. Eur Heart J 2013; 34: 759-766.

159 Naughton MT, Rahman MA, Hara K, et al. Effect of continuous positive airway pressure on intrathoracic and left ventricular transmural pressures in patients with congestive heart failure. Circulation 1995; 91: 1725-1731.

160 Tkacova R, Liu PP, Naughton MT, et al. Effect of continuous positive airway pressure on mitral regurgitant fraction and atrial natriuretic peptide in patients with heart failure. J Am Coll Cardiol 1997; 30: 739-745.

161 Sin DD, Logan AG, Fitzgerald FS, et al. Effects of continuous positive airway pressure on cardiovascular outcomes in heart failure patients with and without Cheyne-Stokes respiration. Circulation 2000; 102: 61-66.

162 Bradley TD, Logan AG, Kimoff RJ, et al. Continuous positive airway pressure for central sleep apnea and heart failure. N Engl J Med 2005; 353: 2025-2033.

163 Arzt M, Floras JS, Logan AG, et al. Suppression of central sleep apnea by continuous positive airway pressure and transplant-free survival in heart failure: a post hoc analysis of the Canadian Continuous Positive Airway Pressure for Patients with Central Sleep Apnea and Heart Failure Trial (CANPAP). Circulation 2007; 115: 3173-3180.

164 Teschler H, Dohring J, Wang YM, et al. Adaptive pressure support servo-ventilation: a novel treatment for CheyneStokes respiration in heart failure. Am J Respir Crit Care Med 2001; 164: 614-619.

165 Pepperell JC, Maskell NA, Jones DR, et al. A randomized controlled trial of adaptive ventilation for Cheyne-stokes breathing in heart failure. Am J Respir Crit Care Med 2003; 168: 1109-1114.

166 Philippe C, Stoica-Herman M, Drouot X, et al. Compliance with and effectiveness of adaptive servoventilation versus continuous positive airway pressure in the treatment of cheyne-stokes respiration in heart failure over a six month period. Heart 2006; 92: 337-342.

167 Cowie MR, Woehrle H, Wegscheider K, et al. Rationale and design of the serve-HF study: treatment of sleepdisordered breathing with predominant central sleep apnoea with adaptive servo-ventilation in patients with chronic heart failure. Eur J Heart Fail 2013 [in press DOI: 10.1093/eurihf/hft051].

168 Ponikowski P, Javaheri S, Michalkiewicz D, et al. Transvenous phrenic nerve stimulation for the treatment of central sleep apnoea in heart failure. Eur Heart J 2012; 33: 889-894.

169 Yamamoto U, Mohri M, Shimada K, et al. Six-month aerobic exercise training ameliorates central sleep apnea in patients with chronic heart failure. J Cardiac Fail 2007; 13: 825-829.

170 Baranchuk A, Healey JS, Simpson CS, et al. Atrial overdrive pacing in sleep apnoea: a meta-analysis. Europace 2009; 11: 1037-1040.

171 Mansfield DR, Solin P, Roebuck T, et al. The effect of successful heart transplant treatment of heart failure on central sleep apnea. Chest 2003; 124: 1675-1681.

172 Scharf SM, Graver LM, Balaban K. Cardiovascular effects of periodic occlusions of the upper airways in dogs. Am Rev Respir Dis 1992; 146: 321-329.

173 Park AM, Nagase H, Kumar SV, et al. Effects of intermittent hypoxia on the heart. Antioxid Redox Signal 2007; 9: 723-729.

174 Joyeux-Faure M, Stanke-Labesque F, Lefebvre B, et al. Chronic intermittent hypoxia increases infarction in the isolated rat heart. J Appl Physiol 2005; 98: 1691-1696.

175 Ramond A, Godin-Ribuot D, Ribuot C, et al. Oxidative stress mediates cardiac infarction aggravation induced by intermittent hypoxia. Fundam Clin Pharmacol 2013; 27: 252-261.

176 Belaidi E, Joyeux-Faure M, Ribuot C, et al. Major role for hypoxia inducible factor-1 and the endothelin system in promoting myocardial infarction and hypertension in an animal model of obstructive sleep apnea. J Am Coll Cardiol 2009; 53: 1309-1317. 